\title{
Reliability of fluid systems
}

\author{
Jaroslav Kopáček ${ }^{1}$, Kamil Fojtášek ${ }^{1, a}$ and Lukáš Dvořák ${ }^{1}$ \\ ${ }^{1}$ VŠB-Technical University of Ostrava, Faculty of Mechanical Engineering, Department of Hydrodynamics and Hydraulic \\ Equipment, 17. listopadu 15/2172, Ostrava 70833, Czech Republic
}

\begin{abstract}
This paper focuses on the importance of detection reliability, especially in complex fluid systems for demanding production technology. The initial criterion for assessing the reliability is the failure of object (element), which is seen as a random variable and their data (values) can be processed using by the mathematical methods of theory probability and statistics. They are defined the basic indicators of reliability and their applications in calculations of serial, parallel and backed-up systems. For illustration, there are calculation examples of indicators of reliability for various elements of the system and for the selected pneumatic circuit.
\end{abstract}

\section{Introduction}

Each machine or technological device is formed from mechanical, hydraulic, pneumatic and electric elements or their combinations, usually coupled with sophisticated proceedings on the basis of electronics and computers. In this case we are talking about the mechanisms, consisting of systems.

Fluid Systems, which is now an established name for hydraulic and pneumatic systems, have in many practical cases the dominant or exclusive position. With the help of fluid systems is realized many manufacturing, assembly, transport, handling and packaging processes. These processes are not only in mechanical engineering, but largely in the food industry, electrical, pharmaceutical and many others. It should be noted that many applications are characterized by high work productivity and also high acquisition and operating costs. It must also consider that, the fluid systems in these applications have a dozens of working elements (linear and rotary actuators) and hundreds control elements with various functions (for pressure control, flow direction, speed, position, etc.), which relate with the function of hundreds of sensors and switches. The failure of a single member of this system leads to a halt operations of a whole manufacturing, assembly or packaging lines. This leads not only to loss of production, but in some cases to the irreversible material losses. And here starts the issue of reliable function of the individual components and the entire system. This issue has not been solved for fluid systems in general or a specific level, in particular in interaction with the electric control circuits.

The issue of reliability of elements and systems, according to available literature elaborated and continuously monitored in the strategic application in military industry (aerospace, missile), in radio engineering and electronics in general, and probably also in the area of large power plants (nuclear power stations). However, as discussed below, reliability is understood as a complex feature which has precisely defined terminology in our, European and world standards and extensive theory of reliability is based on the mathematical theory of probability and statistics.

The theory of reliability deals with three basic tasks:

- forecasting (prediction) of reliability,

- detection of reliability,

- control (diagnosing) of reliability.

For further explanation it is necessary to define the reliability according to universally accepted standards: „Reliability is a general property of an object consisting of the ability to perform the required functions, with maintaining the values specified operating parameters within limits and time set by a technical conditions."

Emphasized the complex property of reliability depends on the inclusion of terms such as durability, repairability, failure rate and many others. This means that reliability cannot be precisely quantified. When providing guarantees of reliability, which is the content of economic contracts, it should be emphasized, that featured an indicator of reliability is for example predicted, anticipated, empirically validated or guaranteed.

The basic criterion for assessing the reliability is the failure of object. This failure is a random phenomenon and means ending the ability of an object (element or the whole system) to perform the desired function from any cause. Failures classification is quite complicated. In terms of reliability and in its time course may be a sudden failure, occasional or sequential. The time course of failure is most commonly demonstrated as bathtub curve

\footnotetext{
${ }^{\mathrm{a}}$ Corresponding author: kamil.fojtasek@vsb.cz
} 
Fig. 1, with three specified courses. The causes of failure are very complicated, and their share of system failure indicates Tab. $1[1]$.

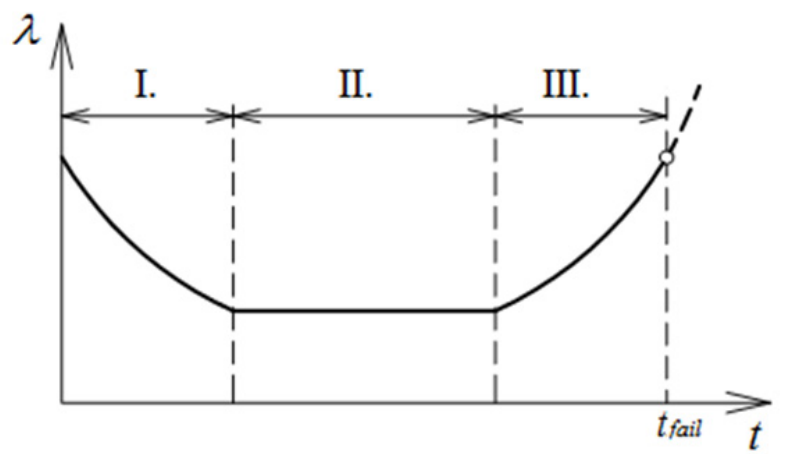

Figure 1. Idealized course of failure per time (bathtub curve)

Table 1. The reasons and causes of failures

\begin{tabular}{|c|c|}
\hline $\begin{array}{l}\text { The nature and causes of } \\
\text { failure }\end{array}$ & $\begin{array}{c}\text { The failure rate } \\
{[\%]}\end{array}$ \\
\hline \multicolumn{2}{|l|}{ a) causes of damage } \\
\hline construction & 20 \\
\hline production & 50 \\
\hline working & 30 \\
\hline \multicolumn{2}{|l|}{$\begin{array}{l}\text { b) character of parameter } \\
\text { changes }\end{array}$} \\
\hline sudden & 40 \\
\hline progressive & 60 \\
\hline predictable & 20 \\
\hline unpredictable & 80 \\
\hline \multicolumn{2}{|l|}{ c) signs of damage } \\
\hline leak & 45 \\
\hline bad settings & 15 \\
\hline lack of functionality & 15 \\
\hline violation of dynamic stability & 10 \\
\hline $\begin{array}{l}\text { destruction of the power } \\
\text { components }\end{array}$ & 15 \\
\hline \multicolumn{2}{|l|}{$\begin{array}{l}\text { d) elements of the hydraulic } \\
\text { system }\end{array}$} \\
\hline pipes and hoses & 35 \\
\hline solenoid coil of valves & 20 \\
\hline automation component & 10 \\
\hline filters & 25 \\
\hline power elements & 10 \\
\hline
\end{tabular}

\section{Theory}

Quantitative evaluation of the reliability of the system is based on the evaluation of the reliability of individual elements. Evaluation is done through a series of characteristics and reliability indicators. These indicators are based on the application of the theory of probability and mathematical statistics.

Our interpretation can significantly simplify and point out the extensive literature in this area. We present four basic relations for evaluating the reliability:

Probability of failure

$$
F(t)=P(\tau<t),
$$

or

$$
F(t)=\int_{0}^{t} f(t) d t
$$

Density of failures

$$
f(t)=\frac{d}{d t} F(t),
$$

the probability of failure-free operation

$$
R(t)=1-F(t),
$$

and intensity of failures

$$
\lambda(t)=\frac{f(t)}{R(t)}=\frac{f(t)}{1-F(t)} .
$$

Intensity of failures is one of the most important indicators of reliability used in practice (the only published value). It should be noted that the $\lambda$ value depends on many factors, especially on production technology, on operating conditions, on the size and complexity of the object and on time, as shown in Fig. 1 [2].

In the last column of Tab. 2 presents the basic theoretical equations, which are supplemented formulas to calculate statistical indicators. In these equations, $n$ is the number of monitored objects, $r$ is the number of damaged objects (objects in failure) and $\Delta t$ is monitored time interval of total time $t$.

The literature indicates a number of values of reliability indicators $\lambda(t)$, apparently obtained empirically, as shown in Tab. 3. Computational application of theoretical equations from Tab. 2 for practical use should be further narrowed to law exponential distribution objects for value $\lambda=$ const., what can be in terms of technical experience to admit.

With these assumptions we obtain practically usable equations [3]:

The probability of failure-free operation

$$
R(t)=e^{-\lambda \cdot t},
$$

density of probability of failure

$$
f(t)=\lambda \cdot e^{-\lambda \cdot t}
$$

The median duration of failure-free operation

$$
T_{s}=\frac{1}{\lambda}
$$

and also

$$
R(t)=e^{-\frac{t}{T_{S}}}
$$


Table 2. Probabilistic definitions and statistical significance of reliability indicators

\begin{tabular}{|l|c|c|c|}
\hline \multicolumn{1}{|c|}{ Indicator of reliability } & Mark & $\begin{array}{c}\text { Determination of } \\
\text { probabilistic }\end{array}$ & $\begin{array}{c}\text { Statistical estimation } \\
\text { (empirical determination) }\end{array}$ \\
\hline Probability of failure-free operation & $R(t)$ & $R(t)=(\tau>t)$ & $R(t)=\frac{n(t)}{n}$ \\
\hline Probability of failure & $F(t)$ & $F(t)=P(\tau \leq t)$ & $F(t)=\frac{r(t)}{n}=\frac{n-n(t)}{n}$ \\
\hline Density of probability of failure & $f(t)$ & $f(t)=\frac{d F(t)}{d t}$ & $f(t)=\frac{r(t)}{n \cdot \Delta t}=\frac{n-n(t)}{n \cdot \Delta t}$ \\
\hline Intensity of failure & $\lambda(t)$ & $\lambda(t)=\frac{f(t)}{R(t)}$ & $\lambda(t)=\frac{r(t)}{n(t) \cdot \Delta t}$ \\
\hline
\end{tabular}

Equation (8) shows that when the median duration of failure-free operation $T_{s}$ is equal to the duration of operation $t$, then $R(t)=e^{-1}=0.37$. Which means that the probability of failure-free operation is reduced to $37 \%$.

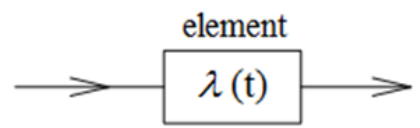

a) block representation

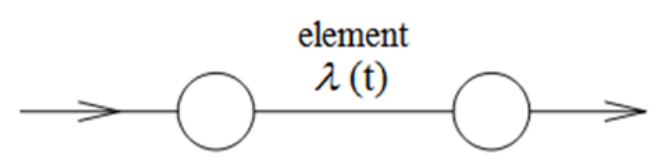

b) representation by oriented graph

Figure 2. Layout of boundary conditions for sliding mesh

For the calculation of the reliability are introduced models in the form of block diagrams or oriented graphs Fig. 2. The individual elements of these models can be connected in series, parallel or series-parallel. For serial connection Fig. 3 is probability of failure-free operation [4]

$$
R(t)=\prod_{i=1}^{n} R_{i}(t)=\prod_{i=1}^{n} e^{-\lambda_{i} \cdot t_{i}},
$$

intensity of failure

$$
\lambda(t)=\sum_{i=1}^{n} \lambda_{i}(t)
$$

and probability of failure

$$
F(t)=1-R(t)=1-\prod_{i=1}^{n}\left[1-F_{i}(t)\right] .
$$

Median duration of failure-free operation (duration to the failure)

$$
T_{s}=\int_{0}^{\infty} R(t) d t=\frac{1}{\lambda(t)}
$$

and then

$$
R(t)=e^{-\frac{t}{T_{s}}}
$$

For parallel connection we have more complicated equations:

probability of failure-free operation

$$
R(t)=1-\prod_{i=1}^{m}\left(1-e^{-\lambda_{i}(t)}\right),
$$

probability of failure

$$
F(t)=\prod_{i=1}^{m}\left(1-e^{-\lambda_{i}(t)}\right),
$$

intensity of failure

$$
\lambda(t)=\frac{F(t)}{1-F(t)} \cdot \sum_{i=1}^{m} \frac{f_{i}(t)}{F_{i}(t)}
$$

and median duration of failure-free operation

$$
T_{s}=\int_{0}^{\infty} R(t) d t
$$

In parallel reliability models are certain elements simplified backup (redundancy), most often in their control part. Assuming that a backup is performed the same element (with intensity $\lambda_{1}=\lambda_{2}=\lambda_{3} \ldots \lambda_{0}$ ), and if this element is also under load, then the probability of failure-free operation of the system [5]

$$
R(t)=e^{-\lambda_{0} \cdot t} \cdot\left(2-e^{-\lambda_{0} \cdot t}\right),
$$

probability of failure

$$
F(t)=1-R(t)
$$

and median duration of failure-free operation

$$
T_{s}=\frac{3}{2 \cdot \lambda_{0}}
$$




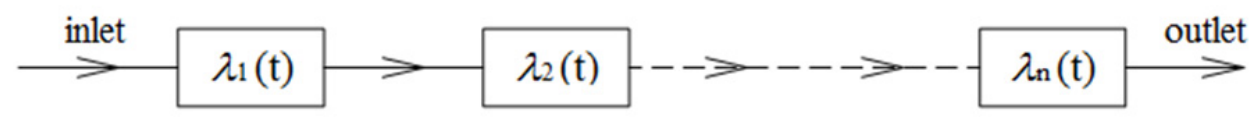

a) block representation

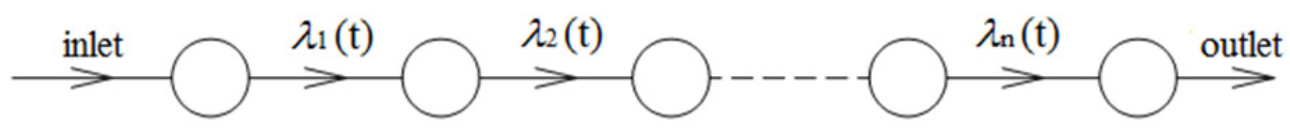

b) representation by oriented graph

Figure 3. Serial reliability diagram

Table 3. Description of the variant

\begin{tabular}{|l|c|c|c|}
\hline Element & \multicolumn{3}{|c|}{ Intensity of failure $\lambda(t) 10^{-6} h^{-1}$} \\
\hline Gear pump & maximum & median. & minimum \\
\hline Axial piston pump & - & 13 & - \\
\hline Rotary hydraulic actuator & 13 & 9 & 6 \\
\hline Linear hydraulic actuator & 7.15 & 4.3 & 1.45 \\
\hline Relief valve & 0.12 & 0.08 & 0.005 \\
\hline Overflow valve & 14.1 & 5.7 & 0.224 \\
\hline Electrohydraulic servo valve & 0.24 & 0.5 & 0.26 \\
\hline Check valve & 56 & 30 & 16.8 \\
\hline Spool valve & 14.1 & 5.7 & 3.27 \\
\hline Accumulator & 0.112 & 0.054 & 0.041 \\
\hline Rubber high-pressure hoses & 7.5 & 6.8 & 0.35 \\
\hline Filtres & 3.27 & 2 & 0.05 \\
\hline Hydraulic tank & 1.69 & 0.79 & 0.01 \\
\hline Static seal & 2.52 & 1.5 & 0.48 \\
\hline Dynamic seal & 7.6 & 4.9 & 2.2 \\
\hline Pneumatic regulators & 1.12 & 0.7 & 0.25 \\
\hline Pneumatic cylinder & - & 2.4 & - \\
\hline
\end{tabular}

If backup element isn not under load

$$
R(t)=e^{-\lambda_{0} \cdot t} \cdot\left(1+\lambda_{0} \cdot t\right),
$$

and

$$
T_{s}=\frac{2}{\lambda_{0}} .
$$

For series-parallel connection are calculation equations more complicated and they are based on the progressive solution of serial and parallel parts. The resulting equations for the overall probability are multiplication of partial solutions.

For the calculation of reliability of complex systems are used mathematical methods and procedures. In literature are mentions about various calculation software. In literature are mentions about various calculation softwares.

\section{Examples of calculation of reliability indicators}

These calculations are performed in the newly designed systems, but also in existing systems (under the operating loads). Usually there is not enough partial information on individual elements, which may be best obtained experimentally (which relates to hydraulic and pneumatic systems). For this reason, calculation focuses only on some indicators of reliability. The most commonly is known the value of intensity of failure $\lambda(t)$. According to this value is verified probability of failure-free operation $R(t)$ and median duration of failure-free operation $T_{s}$.

Quite often in the individual elements of the system (electrical, hydraulic or pneumatic) it is given „lifetime“" value. This value is often confused with the parameter of reliability, expressed in hours of operation (pumps), in number of working cycles (directional valves), or like distance (fictitious stroke) in kilometers for linear motors.

Then time $t$ is replaced to mark $h$ and probability of failure-free operation will be

$$
R(t)=e^{-\frac{h}{T_{s}}}
$$

for example when fictious value $h$ is equal median duration of failure-free operation $T_{s}$, then $R(t)=e^{-1}=$ 0.37. In this case the element will be working without failure only for $37 \%$ of duration $T_{s}$, where $T_{s}$ was calculated from equation (7).

The equation (23) could be modified by the help of known value $\lambda(t)$ 


$$
R(t)=e^{-\frac{\lambda \cdot h}{0.37}}=e^{-2.7 \cdot \lambda \cdot h} .
$$

If we choose intensity of failure $\lambda(t)$ for hydraulic cylinder from Tab. $3 \lambda(t)_{\max }=0.12 \cdot 10^{-6} h^{-1}$ and if we assume a working operation 6000 hours per year, then probability of failure-free operation will be

$$
R(t)=e^{-2.7 \cdot \lambda \cdot h}=e^{-2.7 \cdot 0.12 \cdot 6 \cdot 10^{-3}}=0.998,
$$

which is close to $100 \%$ reliability and this value should not dramatically reduced in next two or three years of working.

For electrohydraulic servo valve with maximal value of intensity of failure $\lambda(t)=56 \cdot 10^{-6} h^{-1}$ Tab. 3, and with working operation $t=h=6000 h$

$$
R(t)=e^{-2.7 \cdot \lambda \cdot h}=e^{-2.7 \cdot 56 \cdot 6 \cdot 10^{-3}}=0.403,
$$

and for redundant servo valve, whose backup control element (electrical, hydraulic) is also under load $\lambda_{1}(t)=$ $\lambda_{2}(t)=\lambda_{0}$. Probability of failure-free operation of element with backup

$$
\begin{gathered}
R(t)=e^{-2.7 \cdot \lambda_{0} \cdot h} \cdot\left(2-e^{-2.7 \cdot \lambda_{0} \cdot h}\right) \\
R(t)=e^{-2.7 \cdot 56 \cdot 6 \cdot 10^{-3}} \cdot\left(2-e^{-2.7 \cdot 56 \cdot 6 \cdot 10^{-3}}\right) \\
R(t)=0.643,
\end{gathered}
$$

which is about $50 \%$ more value probability of failure-free operation than servo valve without backup.

And now one practical example. In the company ZTS Dubnica which produced axial piston convertors was processed sophisticated collection of information about their operation in various working machines. This is of the examples of evaluation that was performed in accordance with the then current standards.

Total production listed convertors was 55773 pieces. Of that number 220 pieces was defective (unrepaired and eliminated). For the calculation will apply values and calculation formulas from Tab. 2 :

Time interval of monitoring $\Delta t=1$ year $=$ 200 days $x 8$ hours of operation $=1600$ hours., the number of monitored convertors $n=55773$, the number of defective and eliminated convertors in time interval $r(t)=220 \mathrm{pcs}$, the number of convertors without failure in this time interval $n(t)=n-r(t)=$ 55553 pcs. Calculated indicators of reliability: Probability of failure-free operation

$$
R(t)=\frac{n(t)}{n}=\frac{55553}{55773}=0.996,
$$

probability of failure in time interval $\Delta t$

$$
F(t)=\frac{r(t)}{n}=\frac{220}{55773}=0.00394
$$

density of probability of failure in time interval $\Delta t$

$$
\begin{gathered}
f(t)=\frac{r(t)}{n \cdot \Delta t}=\frac{220}{55773 \cdot 1600}= \\
f(t)=2.465 \cdot 10^{-6} h^{-1},
\end{gathered}
$$

intensity of failures in time interval $\Delta t$

$$
\begin{aligned}
\lambda(t)=\frac{f(t)}{R(t)} & =\frac{r(t)}{n(t) \cdot \Delta t}=\frac{220}{55553 \cdot 1600} \\
\lambda(t) & =2.474 \cdot 10^{-6} h^{-1}
\end{aligned}
$$

which is significantly lower value than that mentioned in Tab. 3, and indicates a high level of production of the convertors.

We present an application example of calculating the reliability of the pneumatic system, shown in Fig. 4.

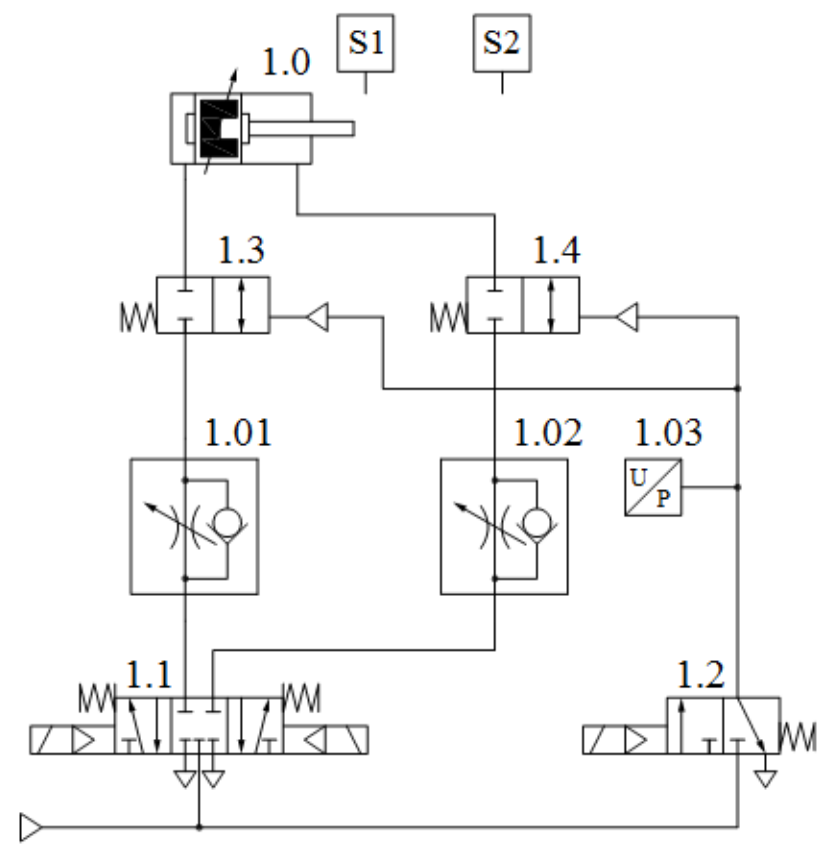

Figure 4. Pneumatic circuit 
Table 4. Description of the variant

\begin{tabular}{|c|c|c|}
\hline & Element & Value $\lambda(t) \cdot 10^{-6} h^{-1}$ \\
\hline$\lambda_{1}(t)$ & rubber hose & 3.27 \\
\hline$\lambda_{2}(t)$ & spool valve & 0.112 \\
\hline$\lambda_{3}(t)$ & rubber hose & 3.27 \\
\hline$\lambda_{4}(t)$ & relief valve & 14.1 \\
\hline$\lambda_{5}(t)$ & rubber hose & 3.27 \\
\hline$\lambda_{6}(t)$ & spool valve & 0.112 \\
\hline$\lambda_{7}(t)$ & rubber hose & 3.27 \\
\hline$\lambda_{8}(t)$ & pneumatic cylinder & 0.013 \\
\hline 8 & & $27.417 \cdot 10^{-6} h^{-1}$ \\
\hline$\sum_{1} \lambda(t)=\lambda_{C}$ & & \\
\hline
\end{tabular}

The calculation was performed for input and output channel, both in series connection. From Tab. 3 we choose intensity of failure $\lambda_{1}(t) \div \lambda_{8}(t)$ for each individual element of input channel and determine the sum.

We choose the time to calculate the failure-free operation $t=h=6000 h$.

Probability of failure-free operation $R(t)$

$$
R(t)=e^{-2.7 \cdot \lambda_{C} \cdot h}=e^{-2.7 \cdot 27.417 \cdot 6 \cdot 10^{-3}}=0.641,
$$

median duration of failure-free operation $T_{S}$

$$
\begin{gathered}
T_{s}=\int_{0}^{\infty} R(t) d t=\frac{1}{\lambda_{C}}=\frac{1}{27.417 \cdot 10^{-6}} \\
T_{s}=36474 \mathrm{~h} .
\end{gathered}
$$

Similarly, for the output channel with a slightly different structure of circuit, Fig. 4 the sum is $\sum \lambda(t)=$ $24.147 \cdot 10^{-6} h^{-1}$, probability of failure-free operation $R(t)=0.676$ and median duration of failure-free operation $T_{s}=41413 \mathrm{~h}$.

Prerequisite for the proposed pneumatic circuit that as a whole system will work more than six years without failure, with probability over $60 \%$.

\section{Conclusion}

In the article it was pointed out to the importance of detection of reliability, especially in complex fluid systems for demanding manufacturing and other technologies. The default criterion is the failure of a component (object) of system. This failure is understood as a random variable, their values can be processed using mathematical methods of probability theory and statistics.

It was defined the basic indicators of reliability and their application in calculations of serial, parallel or backup systems. For illustration were shown examples of calculation of the reliability coefficients for the individual elements of the system and for chosen pneumatic circuit.

The aim of article was pointed out to the stillneglected issue of the reliability of hydraulics and pneumatics mechanisms.

\section{Acknowledgements}

This work was supported by the project SP2015/95 of VŠB Technical University of Ostrava.

\section{References}

1- L. Maixner, Z. Kolníková, Spolehlivost automatických výrobních systémů, (1984)

2- T.A. Syricyn, Nadežnost' gidro-i-pnevmoprivodov, (1981)

3- J. Kopáček, Technická diagnostika hydraulických mechanismu, (1996)

4- S.R. Calabro, Základy spolehlivosti, (1965)

5- B. Dodson, D. Nolan, Reliability Engineering Handbook (1999) 